\title{
Looking Back - EASO Is Celebrating Its 30th Anniversary
}

\author{
Hans Hauner ${ }^{\mathrm{a}}$ Euan Woodward ${ }^{\mathrm{b}}$ \\ ${ }^{a}$ Else Kröner-Fresenius-Zentrum für Ernährungsmedizin, Klinikum rechts der Isar, Technische \\ Universität München, Munich, Germany; ${ }^{\text {b} E u r o p e a n ~ A s s o c i a t i o n ~ f o r ~ t h e ~ S t u d y ~ o f ~ O b e s i t y, ~}$ \\ London, UK
}

It is unbelievable that we are celebrating the 30th anniversary of the foundation of EASO this year. It was on the 6th International Congress on Obesity held from September 14-19, 1986 in Jerusalem, when a group of European obesity experts met in the conference center to discuss and decide on the foundation of a European Association for the Study of Obesity (EASO). The participants rapidly agreed on common goals and the organizational framework. Finally, the participants, including one of the authors (HH), signed the original document containing the association's mission. In the same session, the first Executive Committee was formally elected with Per Björntorp from Gothenburg as president, Trevor Silverstone from London as vice president, F. Arnold Gries from Düsseldorf as general secretary, and Bernard Jeanrenaud from Geneva as treasurer.

The obesity community was rather small in those days, and an international conference was held only every 4 years. Noteworthy for younger readers and EASO members, World Wide Web and e-mail communication were neither invented nor imaginable back then. There was only one journal focusing on obesity topics: the International Journal of Obesity. Therefore, there was agreement that a European association would be very helpful to intensify scientific discussion and collaboration among experts across Europe. It was also stated in the founding document that one of the aims would be 'to hold scientific meetings in Europe and study groups as appropriate'. The more general aims included 'to promote research into obesity', 'to facilitate contact between individuals and organisations' and 'to promote action that tackles the epidemic of obesity'.

Starting in 1988 with the 1st European Congress on Obesity in Stockholm chaired by Stephan Rössner, EASO has been organizing annual scientific conferences across Europe as well as many other meetings to facilitate scientific exchange. It took until 1993 before EASO was finally established as a non-profit organization under French law. In 1998, after years of continuous growth and regular rotation of both the Executive Committee and the Council, the General Assembly approved a fundamental change to the by-laws - changing the membership from individuals to national organizations. This was a substantial step forward because all 
Haunera and Woodwardb: Looking Back - EASO Is Celebrating Its 30th Anniversary

members of the affiliated national obesity societies automatically became members of EASO, thereby pushing forward pan-European activities and further disseminating knowledge and experience. The revised by-laws stated the following (political) aims:

- to encourage and support activities related to the research on and the prevention and

treatment of obesity by acting as a coordinating body by representing the European

national organizations affiliated with the International Association for the Study of

Obesity (IASO),

- to facilitate communication between the members of these organizations and to

represent their interests within the IASO and the European Union,

- to organize congresses on obesity in Europe.

In 2001, EASO launched three task forces: Prevention \& Public Health, Obesity Management, and Childhood Obesity. These task forces are still very active, preparing guidelines, position statements and scientific publications, and coordinating educational activities. In 2005, the General Council representing the presidents of the national societies accepted the recommendation of the Executive Committee to incorporate EASO as an English charity. A permanent office was established in London to meet the growing demand for coordination and communication (www.easo.org). The General Council also agreed to divide EASO into three regions: North, Middle and South, each of which is now represented by an elected Regional Vice President on the EASO Executive Committee. In the same year, EASO established the Young Investigators United initiative (now named New Investigators United) to support young colleagues through travel grants, teaching courses, and summer schools.

EASO is in official relations with the WHO Regional Office for Europe, and now has 32 member associations representing more than 5,000 colleagues, who are scientists, physicians, health care practitioners, public health experts, and patients.

Since 2007, OBESITY FACTS has been serving as the official scientific journal for EASO to share science and to publish EASO guidelines and statements. This important collaboration was developed when EASO started to participate as a disseminating partner in EU-funded research projects, and established a scientific advisory board with the aim of supporting research in our field.

Over the past 30 years, EASO has proven to be a true democratic pan-European enterprise, successfully integrating the cultural diversity of Europe and creating a common identity and awareness that obesity poses a challenge to all of us. It is a platform to join efforts for a better understanding and successful treatment of obesity in order to combat its spread across Europe. EASO is constantly evolving to address new challenges and to meet the needs of its members. Our current mission is to reduce the burden of unhealthy weight, and we promote action through collaboration: in advocacy, communication, education, and research.

Thus, looking back on EASO's history reveals an impressive success story and may encourage all of us to tackle current and future challenges in the field of obesity. 